\title{
TERRITÓRIOS DO HISTORIADOR: RECORDAÇÕES E PRÁTICAS DA VIDA ACADÊMICA
}

\author{
Yvone Dias Avelino ${ }^{1}$ \\ “Amo a História. Se não a amasse não seria historiador"²
}

\begin{abstract}
Resumo:
$\mathrm{O}$ artigo aqui apresentado busca recuperar os caminhos percorridos por famosos pesquisadores, desde a verdadeira "revolução" causada pelos historiadores participantes da Escola dos Annales francesa, nas suas diferentes gerações, e como a historiografia incorporou tais ideias, objetos e sujeitos, não apenas os grandes fatos e personagens políticos, mas ideias, costumes, imagens e mentalidades em cada um dos seus períodos. Desde 1929, com Lucien Febvre e Marc Bloch, até a atualidade com Roger Chartier e outros, indo, em cada etapa, em direção a novas abordagens, para a compreensão e interpretação da História em suas temáticas variadas. Com exemplos pontuais de pesquisas, a presente narrativa pretende colaborar com a devida discussão dessas suaves e, às vezes, bruscas mudanças, gerando novos diálogos interdisciplinares e a valorização da subjetividade do pesquisador.
\end{abstract}

Palavras-chave: História. Cultura. Mudança. Temáticas. Abordagens Interdisciplinares.

\section{HISTORIAN TERRITORIES: RECORDS AND PRACTICES OF ACADEMIC LIFE}

\begin{abstract}
:
The article presented here seeks to recover the paths taken by famous researchers, since the true "revolution" caused by the participating historians of the French Annales School, in their different generations, and as historiography incorporated such ideas, objects and subjects, not only the great facts and political characters, but ideas, customs, images and mentalities in each of their periods. From 1929, with Lucien Febvre and Marc Bloch, to the present day with Roger Chartier and others, moving, at each stage, towards new approaches to understanding the interpretation of History in its varied themes. With specific examples of research, this narrative intends to collaborate with the proper discussion of these smooth, and sometimes abrupt changes, generating new interdisciplinary dialogues and the enhancement of the researcher's subjectivity.
\end{abstract}

Keywords: History. Culture. Change. Thematics. Interdisciplinary Approaches.

\footnotetext{
${ }^{1}$ Professora Titular do Departamento de História da PUC/SP. Coordenadora do Núcleo de Estudos de História Social da Cidade - NEHSC da PUC-SP. Editora da Revista Cordis - Revista Eletrônica de História Social da Cidade - www.pucsp.br/revistacordis.

${ }^{2}$ FEBVRE, Lucien. Palestra no Collège de France,Paris, 1930.
} 
A História é um caleidoscópio ${ }^{3}$ de ações humanas, é um romance verdadeiro. Simplifica, organiza, seleciona, registra e analisa. Tem seu suporte na realidade exterior, que tem existência concreta e autônoma, conforme nos elucida Veyne ${ }^{4}$. Dispensa, portanto, artifícios discursivos e estéticos para ser valorizada. É uma narrativa verídica, cujos acontecimentos se submetem ao critério da verdade, ao contrário do discurso ficcional, que é uma questão de verossimilhança.

Se pensarmos desde a verdadeira "revolução" causada pelos historiadores participantes da Escola dos Annales francesa, a historiografia tem incorporado como seus objetos e sujeitos, não apenas os grandes fatos e personagens políticos, mas também as ideias, os costumes, as imagens e as mentalidades de cada período.

A Nouvelle Histoire, como ficou conhecida no último quartel do século XX, foi um movimento surgido inicialmente entre os membros da Revista Annales d'Histoire Economique et Sociale, fundada em 1929 por Lucien Febvre e Marc Bloch, e que, a partir de 1946, passou a se chamar Annales Economies, Sociétés, Civilisations, indo em direção de novas abordagens, para a compreensão da História em suas variedades temáticas e introdução de novas fontes, novas propostas, novas abordagens interdisciplinares e a valorização da subjetividade do pesquisador. Claro que também devemos ressaltar que a questão do método histórico científico é discutida pela Filosofia da História, pela Teoria da História e pela Historiografia.

Ao longo da década de 1930, a Revista Nouvelle Histoire, História Nova, tornou-se símbolo de uma nova corrente historiográfica identificada como Escola dos Annales. A proposta inicial do periódico era de se livrar de uma visão positivista da escrita da História que havia dominado o final do século XIX e início do XX.

Sob essa visão, a História era relatada como uma crônica de acontecimentos. O novo modelo veio para substituir as visões anteriores e apresentar análises de processos de longa duração com a finalidade de permitir uma maior e melhor compreensão das civilizações das "mentalidades".

O novo movimento historiográfico que se apresentava foi renovador ao colocar em questionamentos a historiografia tradicional e justificar novos e riquíssimos elementos para o conhecimento das sociedades.

Nessa direção apresentava a História, mais ampla do que anteriormente era praticada, colocando os mais importantes aspectos possíveis da vida humana ligada à análise das estruturas.

Entre as modificações apresentadas por essa nova proposta, estava a argumentação de que o tempo histórico apresenta ritmos diferentes para os acontecimentos mais simples, conjunturais ou estruturais.

Ao considerar a História não mais apenas como uma sequência de acontecimentos, outros tipos de fontes, como arqueológicas, foram adotados para as pesquisas. Da mesma forma foram incorporados os fatores econômicos, da organização social e da psicologia das mentalidades. Com

\footnotetext{
${ }^{3}$ Caleidoscópio - (do grego Kalos, belo + eidos, imagem + skopen, ver) aparelho formado de um tubo que contém diversos espelhos dispostos de um modo tal, que pequenos objetos coloridos, colocados em seu interior, produzem desenhos variados - Grande Dicionário Larousse Cultural da Língua Portuguesa, SP 1999, Ed. Nova Cultural ${ }^{4}$ VEYNE, Paul. Como se escreve a História. Brasília, Ed. UNB, 1995.
} 
todo esse enriquecimento a Escola dos Annales aproxima a História das demais Ciências Sociais, sobretudo da Sociologia. ${ }^{5}$

O lançamento da revista francesa, Annales d'histoire économique et sociale em 1929, compreende a primeira geração dos Annales (1929 a 1939), que teve como editores o medievalista Marc Bloch e o estudioso do século XVI Lucien Febvre. Nota-se em tal produção a busca de uma nova visão historiográfica que difere da historiografia tradicional positivista que perpetuava até então. Desse modo, os Annales passam a conceber novos métodos de análises que se voltam para uma história questionadora sem respostas prontas em favor de uma abordagem nova e interdisciplinar. Passam a direcionar aos documentos uma análise crítica com a concepção de que estes não constituem uma verdade absoluta.

Tendo o intuito de auxiliar uma visão mais ampla da análise histórica, os Annales promovem a abordagem de outras ciências, o que se compreende por interdisciplinaridade. Tal abordagem provoca inúmeras críticas, questionando se a história ia ser submetida às outras áreas do conhecimento científico, conforme diz Vainfas (1997), “(...) o fato é hoje a chamada Nova História abriu-se de tal modo a 'outros saberes' e questionamentos estruralistas que, no limite, pôs em risco a própria soberania e legitimidade da disciplina (...)" ${ }^{\prime 6}$

Em oposição, alguns historiadores defendem as contribuições da interdisciplinaridade: “Assim, a História Nova é um exemplo típico de interdisciplinaridade, de abertura a diversas áreas do saber. Há um encontro entre duas ou mais disciplinas e o que fica é uma nova visão e experiência $(. . .)^{7}$

Críticas e contribuições à parte, o historiador deve estar atento às duas vertentes:

Se não resta dúvida de que, por um lado a interdisciplinaridade contribuiu muitíssimo, no atual século, para o aperfeiçoamento do saber e da narrativa historiográfica, por outro lado foi muitas vezes mal compreendida. Levada ao extremo, confundida com transdisciplinaridade, ao invés de entendida como diálogo entre disciplinas distintas quanto aos métodos e objetos, pode conduzir a verdadeiros cataclismos teóricos. ${ }^{8}$

Desse modo, da interação com as outras ciências surge a concepção de história total, aspirando novos horizontes para a história:

Assim a grande lição dos Annales, com sua 'exigência' metodológica de uma história total, ou global, e com sua concretização prática desta 'exigência', plasma no difícil projeto de juntar-se $\mathrm{a}$, ou vincular-se muito estreitamente às demais ciências sociais $(. . .)^{9}$

Outro método historiográfico utilizado pelos Analles foi a chamada história-problema, de modo que o historiador parte de problemas evidenciados pelo presente analisados por meio de um retrocesso, ou seja, o historiador parte do presente para questionar o passado. Tal questão

\footnotetext{
${ }^{5}$ BURKE, Peter. A Escola dos Annales: 1929-1989. São Paulo. Editora Universidade Paulista, 1991.

${ }^{6}$ VAINFAS, Ronaldo. História das Mentalidades e Histórias Cultural. In: CARDOSO Ciro Flamarion e VAINFAS, Ronaldo (orgs.) Domínios da História. Ensaios de Teoria e Metodologia. Rio de Janeiro: Campus, 1997, p. 146.

${ }^{7}$ MAROTA OTANI, Claudia de Almeida. O que é História das Mentalidades. São Paulo: Brasiliense, 1997, p. 15.

${ }^{8}$ VAINFAS, op. cit., 1997, p. 145.

${ }^{9}$ AGUIRRE ROJAS, Carlos Antonio. Os Annales e a historiografia francesa: traduções e críticas de Marc Bloch à Michel Foucault. Maringá: Eden, 2000, p. 186.
} 
estava imbuída de concepções que o historiador tem da sociedade em que vive, tendo em vista que não se desprende de sua sociedade atual para analisar o passado. Quanto mais interrogações forem levantadas, a história vai enriquecer suas concepções. Em tal método historiográfico,

(...) Lucien Febvre convida o historiador a inspirar-se nos problemas colocados pelo tempo presente, no qual ele vive, pensa e escreve. A interrogação do passado a partir do presente tem para os Annales valor heurístico (...) O presente ajuda a pesquisa do passado e permite valorizar uma história-problema e enriquecer o conhecimento do passado. ${ }^{10}$

O movimento dos Annales ainda em sua primeira geração (1929-1939) vinculava e inovava por meio de uma preocupação com o estudo do mental, alinhavado à questão cultural. Tal preocupação é evidente nos estudos de Lucien Febvre, que tem como tema privilegiado o Renascimento e a Reforma, sob a perspectiva da relação entre indivíduo e sociedade, no qual abordava questões religiosas do século XVI, com a obra de escritores franceses como Rabelais e Margarida de Navarra.

No estudo sobre a obra de Rabelais, Febvre conclui que este era um singular crítico da Igreja e se opõe à ideia de heresia, já que o autor percebe em seus estudos,"(...) a impossibilidade, ou melhor, a dificuldade de se desenvolver um pensamento que fosse autônomo em relação à herança cristã." 11

Já em relação aos estudos realizados em torno de Margarida de Navarra, afirma que esta não perdeu sua religiosidade ao escrever uma obra tida como imoral para a época, apenas a percebeu como um indivíduo imbuído em seu contexto social. De modo que sua ambiguidade (ser religiosa e ao mesmo tempo profana) era uma característica do século XVI, cujo período o autor percebe como uma "(...) época de crise de valores, que convivem o fervor das crenças e as querelas entre a religião e a vida profana." 12

A preocupação com o estudo do mental também pode ser evidenciada na obra de Bloch $^{13}$, Os Reis Taumaturgos, que abordava a crença de que os reis podiam curar doentes por meio do toque real, obra essa difundida na Inglaterra e França do século XIII ao XVIII. Publicada na década de 1920, a obra distingue-se em relação aos estudos históricos do período. Bloch busca, por meio de uma temática tida como marginal, compreender a ideia política, ou seja, consegue integrá-la em um contexto global, não isolando o objeto de análise e nem o deixando desvinculado de seu contexto. Tal análise que inseria o mental no âmbito social e vai ser ofuscada principalmente na chamada terceira geração.

A chamada história de longa duração proposta por Braudel e presente na segunda geração dos Annales (1956 a 1969) insere-se no contexto pós-Segunda Guerra Mundial, em que a historiografia passou a privilegiar mais intensamente o aspecto econômico e social. Nesse período ocorreu a chamada explosão das ciências sociais e a história se percebeu questionada como ciência maior do social. O diretor da Revista da segunda geração dos Annales, Braudel, respondeu a tais questionamentos com a mudança das pesquisas históricas, dando-lhe um caráter estrutural que difere da estrutura compreendida pelos sociólogos. Para Braudel, a estrutura é compreendida pelos historiadores pela permanência temporal, ou seja, o que resiste

\footnotetext{
${ }^{10}$ DOSSE, François. A História em Migalhas - dos Annales à Nova História. São Paulo: Unicamp, p. 67.

${ }^{11}$ RAMINELLI, Ronald. Lucien Febvre no caminho das mentalidades. São Paulo: Revista de História, n ${ }^{\circ} 22$, jan/julho, 1990, p. 122.

${ }^{12}$ RAMINELLI, op. cit, 1990, p. 108.

${ }^{13}$ BLOCH, Marc. Os reis taumaturgos. São Paulo: Vozes, 1962.
} 
ao tempo e se transforma lentamente. O historiador é capaz de ter acesso às estruturas profundas da sociedade, superando a análise tradicional da História que valorizava o tempo curto das rupturas e transformações. Desse modo, Braudel inovou com a noção de tempo histórico em três níveis inter-relacionados, ou seja, durações. Tais durações se definem por tempo curto, tempo médio e tempo longo. A chamada longa duração confere significados às lentas transformações da história.

A história de longa duração vai trazer alguns riscos para o historiador, como exemplificou Ronald Raminelli:

Ou melhor, o estudo dos fatos recuados no tempo se torna perigoso à medida em que se afasta do presente do historiador (sobretudo quando se aborda as mentalidades). Neste caso, pode-se facilmente incorrer em erros de anacronia, ou melhor, atribuir a esses homens características que são peculiares à nossa época e, consequentemente, estranhas ao tempo estudado. ${ }^{14}$

Em relação aos aspectos econômicos, a segunda geração foca em estudos pautados pela estatística, qualificação e demografia. Ambas as gerações se pautam pela história global, a história problema e de longa duração. Falar da pesquisa em História, sua rica metodologia e seus temas mais frequentes na historiografia dos anos 70, 80 do século XX é reviver a própria vida e o conhecimento adquirido na Universidade de São Paulo e as pesquisas iniciais realizadas nesse período. Somos filha das duas importantes correntes historiográficas, os Annales e o Marxismo como tão bem apontou Sandra Pesavento (2014).

Foi nessas discussões e no topo dos resultados de pesquisa muito explorados nessas décadas que nos debruçamos em uma árdua busca que não resultasse de simples pesquisa, mas também de profunda reflexão. Acreditamos que um trabalho de pesquisa é necessariamente científico, mas ousado, na medida em que o historiador tem o dever de pesquisar para poder inovar. Para tal buscamos um tema - A prata de Vera Cruz na época do "Comércio Livre", como exemplificação concreta para a demonstração de uma determinada problemática. Nosso propósito consistiu em partir, antes de tudo, para o estudo das mudanças estruturais do sistema colonial espanhol, culminadas, afinal, com a Instituição do "Comércio Livre, em 1778 no reinado de Carlos III.

Esta foi uma pesquisa que resultou em um doutorado e um carro chefe para outras neste contexto. ${ }^{15}$

A terceira geração dos Annales, que compreende o período de 1969 a 1989, apresenta certa descontinuidade entre a análise historiográfica das gerações anteriores.

Inúmeras críticas historiográficas dirigem-se à terceira geração por tratar o objeto de análise, esmiuçando-o, isolando-o e o desvinculando de seu contexto; de certa forma, diferindose das análises historiográficas das gerações anteriores que preconizavam a integração do objeto com o todo, ou seja, sua relação com o contexto social.

Dentre tais críticas que se dirigem à terceira geração é pertinente expor François Dosse. ${ }^{16}$ Para Dosse, a História da Vida Privada encontra-se imbuída de um modismo e propaganda. Tal tendência desenvolveu-se desde a década de 1970 com a terceira geração dos Annales, quando ocorreu uma abertura do leque de possibilidades de pensar e fazer história, ou

\footnotetext{
${ }^{14}$ RAMINELLI, op. cit., 1990. p. 98.

${ }^{15}$ PESAVENTO, Sandra. História e História Cultural, Belo Horizonte: Autêntica Editora, 2014.

${ }^{16}$ DOSSE, op. cit., 1992.
} 
seja, abrem-se novos campos como o quantitativo, o cultural, a psico-história; além da microhistória e a aproximação com a história antropológica. A problemática exposta é a de que a terceira geração dos Annales, ao dar ênfase à antropologia, à história das mentalidades e do cotidiano, particularizou a história estudando um grupo de pessoas ou um único indivíduo. $\mathrm{O}$ problema está em que estudar apenas um grupo de pessoas ou um único indivíduo, a história se congela de modo que não há transformação.

É possível compreender um conjunto por meio de uma análise histórica fragmentada como a problemática explicitada nos estudos de Dosse, ou seja, é possível compreender o conjunto com base em uma análise que parte do específico.

Para argumentar sobre tal questionamento, apontamos o trabalho de Mary Del Priore, que defende uma análise pormenorizada do objeto, mas compreendendo a possibilidade de relação com o conjunto. A autora aponta a possibilidade de se compreender o geral por meio do específico com o auxílio da antropologia histórica, elaborando uma história pautada pela transformação:

Com o auxílio da antropologia histórica, o cotidiano e a vida privada permitem ser analisados numa abordagem global, que atribui a cada autor e a cada elemento da realidade histórica um papel no funcionamento dos sistemas que permitem a decifração desta realidade. A antropologia corresponde à necessidade de encontrar, no cotidiano e na vida privada, diferentes formas de transformação, de fazer seu inventário, de compreender seus mecanismos e afirmar sua pluralidade. ${ }^{17}$

Para Mary Del Priore, a vida privada se tornou visível no século XVIII, período em que se estabelecem as relações burguesas ditadas pelas práticas capitalistas. Segundo a autora, "No sentido comum, o termo remete, com imediatismo à vida privada e familiar, às atividades ligadas à manutenção dos laços sociais, ao trabalho doméstico e às práticas de conumo." 18

É nesse ambiente familiar e cotidiano que a sociedade burguesa atua sem as amarras da vida pública, meio em que se realizam as práticas produtivas e a luta de classe e, de certa forma, estabelece suas relações. Desse modo, a autora relaciona uma análise pautada pelo específico para a compreensão do todo, ou seja, para a compreensão da sociedade burguesa.

Como pode ser observado em seus estudos, a autora analisou a vida privada com base nas críticas direcionadas à História das Mentalidades. A Nova História Cultural passou a sugerir diversas mudanças em relação ao estudo do mental, como a preocupação com o popular, valorização da estratificação e dos conflitos sociais. Outro trabalho que percorre trajetória semelhante é o estudo de Margareth Rago sobre a prostituição em São Paulo entre 1890 e 1930. Através da análise da prostituição, Rago consegue compreender a sociedade e suas transformações em curso, como explica “(...) tentarei perceber em que a presença das cortesãs, muitas das quais estrangeiras, afetou o imaginário social, tendo em vista as próprias mudanças sociais e culturais que atingiram a condição da mulher na cidade de São Paulo"19

Ainda sobre a relação dos estudos entre Dosse, Mary Del Priore e Margareth Rago, em geral Dosse refere-se aos limites e riscos dos estudos pautados pelo específico que, segundo

\footnotetext{
${ }^{17}$ PRIORE, Mary Del. História do Cotidiano e da Vida Privada, in: CARDOSO, Ciro Flamarion. (Org.) Domínios da História. Ensaio de Teorias e Metodologias, Rio de Janeiro: Campus, 1997, p. 271.

${ }^{18}$ PRIORE, op. cit, 1997, p. 270.

${ }^{19}$ RAGO, Margareth. Os prazeres da noite: prostituição e códigos da sexualidade feminina em São Paulo. 1890 - 1930, Rio de Janeiro: Paz e Terra, 1991. p. 25.
} 
o autor, compreende uma história de migalhas, ou seja, fragmentada. Enquanto Mary Del Priore e Margareth Rago apontam suas possibilidades e importância.

Inaugurada pela primeira geração e pouco evidenciada pela segunda, a denominada História das Mentalidades ganha outras possibilidades e vertentes na terceira geração.

Devido às diversas críticas direcionadas à história das mentalidades que busca conceber uma mentalidade coletiva tida como homogênea e não levando em consideração as particularidades e diferentes classes sociais, ou seja, “(...) apregoar que a mentalidade é algo comum ao conjunto da sociedade, não importando o lugar ocupado por indivíduos ou grupos na estratificação social (César e o soldado romano, São Luís e o camponês etc.)."20

Esta passa a assumir a definição de Nova História Cultural que adentra a preocupação com o popular, estratificação e conflitos sociais. A denominada Nova História Cultural não nega o estudo do mental desde que se viabilizem tais preocupações, ou seja, a conexão com a sociedade. Como argumenta Ronaldo Vainfas, ao citar a afirmação de Ginzburg:

(...) Insistindo nos elementos comuns, homogêneos, da mentalidade de em certo período, somos inevitavelmente induzidos a negligenciar as divergências e o contraste entre as mentalidades das várias classes, dos vários grupos sociais, mergulhando tudo numa mentalidade coletiva indiferenciada e interclassista. ${ }^{21}$

$\mathrm{O}$ autor elaborou um estudo sobre um moleiro, pertencente às classes populares, condenado como herege pela Inquisição Papal do séc. XVI. Foi nessa pesquisa que o historiador abandonou o conceito de mentalidade e adotou o de cultura popular, ou seja, uma continuidade do processo. De início apresentou as dificuldades encontradas pelo historiador em viabilizar um estudo sobre tal classe. Tendo em vista a escassez de documentos e quando são encontrados derivam de fontes escritas em geral de autoria da classe dominante, segundo o autor:

Ainda hoje a cultura das classes subalternas é (e em muito mais, se pensarmos nos séculos passados) predominantemente oral (...). Precisam então servir-se, sobretudo, de fontes escritas (e eventualmente arqueológicas) que são duplamente indiretas por serem escritas e, em geral, de autoria de indivíduos, uns mais ou menos, abertamente ligados à cultura dominante. Isso significa que os pensamentos, crenças, esperanças dos camponeses e artesãos do passado chegam até nós através de filtros e intermediários que os deformam. ${ }^{22}$

Desse modo, mesmo a fonte sendo de certa forma filtrada, não significa que a documentação seja inútil, o que induz hoje muitos historiadores a deixarem de lado as metáforas, a cultura popular junto com a documentação, que dela nos dá uma imagem mais ou menos deformada.

No desenvolver de sua análise sobre o moleiro Menochio, tal obstáculo é superado, pois há a compreensão de que existe uma circularidade cultural, ou seja, os dois polos culturais constituídos pela cultura popular e erudita não se distinguem, pelo contrário, convergem, existindo uma influência recíproca entre as duas culturas:

Mas a cultura popular se define também, de outro lado, pelas relações que mantém com a cultura dominante, filtrada pelas classes subalternas de acordo

\footnotetext{
${ }^{20}$ VAINFAS, op. cit., 1997, p. 149.

${ }^{21}$ GINZBURG, Carlo. O queijo e os vermes: o cotidiano e as ideias de um moleiro perseguido pela Inquisição. São Paulo: Cia das Letras, 1987, p. 18.

${ }^{22}$ Idem, Ibidem, 1987, p. 22.
} 
com seus próprios valores e condições de vida. É a propósito desta dinâmica entre os níveis culturais do popular e erudito - já que também a cultura letrada filtra à sua moda os elementos da cultura popular -, que Carlos Ginzburg propões o conceito de circularidade cultural. ${ }^{23}$

Menochio personifica o processo de circularidade cultural presente num indivíduo que filtrou valores da classe dominante e os interpreta de acordo com sua concepção de vida, ou seja, de indivíduo inserido no âmbito social.

Outro método que contribui para a percepção da cultura popular é a história oral. Por meio dos relatos podemos adentrar em um universo específico que constrói suas próprias visões de vida e de mundo, mas que, apesar de construir visões próprias, não está destacado da ideia de circularidade cultural, ou seja, em tais construções existe uma influência recíproca entre as classes. Essa dinâmica entre os níveis culturais evidenciados por Carlo Ginzburg evitou ou pelo menos apontou o obstáculo em desenvolver uma pesquisa baseada em uma visão dicotômica da história como cultura popular e erudita, classe dominada e dominante ou ainda vencidos e vencedores. Por meio da História Oral podemos rejeitar as dicotomias e obter uma multiplicidade de histórias dentro da história reconhecendo sua diversidade. Podemos apontar o brilhante trabalho organizado pelos eminentes historiadores Ciro Flamarion Cardoso e Ronaldo Veinfas ${ }^{24}$ que, com a colaboração de competentes pesquisadores nos presenteiam com diferentes possíveis temáticas com a contribuição da recente História Cultural.

Não podemos deixar de colocar também a importante contribuição do livro de Carla B. Pinsky e Tania Regina de Luca $^{25}$ que contou também com a colaboração de vários e competentes pesquisadores que utilizaram variados documentos e suas metodologias nas pesquisas históricas.

São abordagens específicas, com métodos diferenciados e variadas técnicas que também muito contribuíram para a elaboração de artigos e pesquisas importantes e variadas nos cursos de pós-graduação stricto-sensu.

Falar da pesquisa em História, sua rica metodologia e seus temas mais frequentados na historiografia contemporânea é reviver a própria vida e o conhecimento adquirido ao longo dos nossos anos de docente e as pesquisas iniciais realizadas nesse contexto. Somos formadas nas duas importantes correntes historiográficas, os Annales e o Marxismo, duas colunas importantes que nos deram grandes contribuições para nos apoiar nas reflexões e resultados em nossas modestas contribuições à historiografia.

Com todos esses apontamentos acima expostos neste artigo, os anos 80, o Programa de Estudos Pós-Graduados em História da Pontifícia Universidade Católica de São Paulo PUC-SP, depois de algumas reuniões e discussões entre os pares, optou por mudar as suas linhas de pesquisa de "Movimentos Sociais" e "Ideologia", compostas por reflexões de cunho iminentemente marxista, para o eixo central História e Cultura, criando as linhas de pesquisa que ainda hoje fazem parte de seu currículo: "Cultura/Cidade", "Cultura/Trabalho" e "Cultura/Representação". Essas mudanças ocorreram pelo interesse despertado entre os historiadores nos novos estudos em História Cultural, que implicavam representações e

\footnotetext{
${ }^{23}$ GINZBURG, op. at, 1987, pg 22.

${ }^{24}$ CARDOSO, Ciro Flamarion, Veinfas Ronaldo (Orgs.) Domínios da História: ensaios de Teoria e Metodologia. Rio de Janeiro: Campus, 1997.

${ }^{25}$ PINSKY, Carla B. e LUCCA, Tania Regina de (Orgs.) Historiador e suas fontes. São Paulo: Contexto, 2009.
} 
bifurcações das preocupações da História Social, com orientação marxista, e a nova corrente, com uma virada e abordagem linguística, ou seja, uma releitura dos conceitos de História Social.

Vários outros Programas no Brasil, cujas linhas de pesquisa eram em História Social e História Econômica passaram para o eixo da História Cultural. Outros Programas que foram surgindo centrara-se diretamente na História Cultural. Segundo indicações do Professor Doutor Diogo da Silva Roiz, pesquisador do Departamento de História da Universidade Estadual de Mato Grosso do Sul - UEMS, “(...) as pesquisas nos últimos vinte anos estão concentradas em História Cultural, perfazendo um total de $80 \%$ de tudo que tem sido produzido nas Universidades brasileiras, tornando-se uma temática constante no mundo inteiro."26

Desde então, observamos uma riqueza de produções nessa área, gerando um imenso lucro para o mercado editorial, dadas as éticas deveras significativas que se desdobram, que seduzem o leitor e implicam hipertextos, ou seja, uma obra remete o leitor à outra, que remete à outra e assim por diante, envolvendo uma sociedade que antes, talvez, não tivesse tanto interesse pelos títulos apresentados. Então, usando uma expressão popular, poderíamos dizer que a História se "desbloqueou", estabelecendo diálogos importantes e substanciosos com vários ramos do conhecimento, exercendo nos agentes dessas relações o inter, o multi e o transdisciplinar.

Nesse contexto debruçamo-nos sobre a História Oral em uma pesquisa sobre a História da Pontifícia Universidade Católica de São Paulo que resultou em uma publicação e em apresentações em Encontros e Simpósios. A PUC/SP completava setenta anos em agosto de 2016. O valor e os significados desse momento ímpar sobre tão importante Universidade levaram a comunidade puquiana a iniciar em 22 de agosto de 2015 os eventos acerca desse marco.

Assim, sendo, como integrantes do Núcleo de Estudos de História Social da Cidade NEHSC - PUC/SP, queríamos também homenagear essa insigne Instituição de Ensino Superior, onde as ideias sempre foram plurais, em um palco de culturas, saberes e lutas. Essa publicação à que nos referimos ${ }^{27}$ trata-se de um mosaico de História de Vidas, cujos personagens vivenciaram em épocas distintas a História desta Universidade, desde a sua criação até os dias atuais daquela data.

Foram importantes os agentes que nos ajudaram a construir e publicar essa pesquisa já inserida em uma outra metodologia, diferente da utilizada no exemplo acima referido, em que aplicamos o quantitativo de Braudel. Aqui nos referirmos a essa pesquisa, a História Oral foi utilizada como técnica, pois para alguns historiadores é método, e que utilizamos como os ensinamentos das novas propostas em História Cultural.

Apresentávamos, então, os resultados de uma investigação sobre o nascedouro e o desenvolvimento da Pontifícia Universidade Católica de São Paulo (PUC/SP) por meio do uso da Documentação Oral, técnica complementar da pesquisa ligada à elaboração de documento contemporâneo.

\footnotetext{
${ }^{26}$ ROIZ, Diogo da Silva. A Nova História Cultural. Questões e debates. In: Pensamento Plural. Pelotas: jan/jun, 2008, p. 181.

${ }^{27}$ AVELINO, Yvone Dias et alii. (Orgs.). No laboratório das palavras História da Pontifícia Universidade Católica de São Paulo, coletânea de documentos (1979-1985).
} 
Se pensarmos a História e o papel do historiador ao utilizar a narrativa para produzir as mais diversas interpretações de um acontecimento, estabelecemos a recuperação dos cacos e dos ruídos polifônicos do passado, de modo a criar uma relação nem sempre apaixonante, mas extremamente necessária. O historiador, ao buscar outras áreas de conhecimento que o seduzam, dialoga com elas. Contudo, não abandona o elemento documental, mesmo ao se afastar momentaneamente da História, o que nos permite observar que há sempre, parafraseando Mircea Elíade, um eterno retorno à História. ${ }^{28}$

O historiador encontra um universo rico, de múltiplas interpretações, através de um fio condutor, que o leva a conclusões por meio de percalços, como sustos, alegrias, sobressaltos e rupturas. Como pensa Certeau, (...) o historiador se instala na fronteira onde à lei de uma inteligibilidade, encontra seu limite como aquilo que deve incessantemente ultrapassar $(. . .)^{29}$

Buscando inspiração em Franz Boas, que no início do século XX fez uma aproximação entre História e Antropologia, ${ }^{30}$ até hoje bastante utilizada, chegando a influenciar obras como Casa Grande \& Senzala, de Gilberto Freyre,${ }^{31}$ discípulo de Boas, acreditamos que a guinada para a História Cultural permitiu ao historiador avanços mais expressivos nos diálogos constantes com outras áreas, que antes não se atrevia a fazer. ${ }^{32}$

A definição de Cultura nem sempre vem da Antropologia. Alfredo Bosi define-a com base na linguística e na etimologia da palavra cultura/culto/colonização, verbo latino "colo", que significa "eu ocupo a terra", não só no sentido de agricultura, mas na produção de valores e conhecimentos. Na segunda metade do século XX, com a História Nova, e as conexões entre a História e outras áreas do conhecimento, com temas mais voltados para o cotidiano e as mentalidades, proliferam-se os trabalhos em História Cultural. É correto afirmar que a História Cultural é, na realidade, aplicação de um outro nome para aquilo que nos anos 70 era chamado de "História das Mentalidades" como afirmamos nas páginas anteriores. Esta História Cultural resulta em uma especial afeição pelo informal e, sobretudo, pelo popular, ou melhor, pela popularização, ou seja, pelo encontro e disseminação dos saberes.

Um exemplo disso em histórias mais recentes é "O Grande Massacre dos Gatos", de Roberto Darnton, ${ }^{33}$ que visita a sociedade francesa do século XVIII. Também podemos apontar o historiador americano Lynn Hunt, com sua obra "A Nova História Cultural", ${ }^{34}$ produzida em quatro ensaios, onde analisa a história da cultura à moda de Foucault, a história da cultura dos "historiadores", comparando as ideias de Thompson e Natalie Davis, a história da cultura de inspiração antropológica, comparando Geertz e Sahlins, e a história cultural relacionada à crítica literária e a discussão das relações entre história e literatura, comparando Hayden White e Dominick La Capra. Ou seja, no conjunto da obra, comprova o autor a citada pluralidade e dissemina a História Cultural.

Citamos acima também o italiano Carlo Ginzburg, com a obra "o Queijo e os Vermes", que defende a cultura popular ou circularidade cultural.

\footnotetext{
${ }^{28}$ ELÍADE, Mircea. O Mito do Eterno Retorno. Lisboa: Edições 70, 1999.

${ }^{29}$ CERTEAU, Michel de. A Escrita da História. Rio de Janeiro: Forense-Universitária, 1982.

${ }^{30}$ CASTRO, Celso. (Org.) Antropologia Cultural/Franz Boas. Rio de Janeiro: Zahar, 2010.

${ }^{31}$ FREYRE, Gilberto. Casa Grande e Senzala. Formação da família brasileira sob o regime de economia patriarcal. Rio de Janeiro: Livraria José Olimpio, 1961.

${ }^{32}$ BOSI, Alfredo. A Dialética da Colonização. São Paulo: Cia. das Letras. 1992.

${ }^{33}$ DARNTON, Roberto - O grande massacre dos gatos. São Paulo: Grupo Editorial Record, 1985.

${ }^{34}$ HUNT, Lynn. A nova História Cultural. São Paulo. Ed. Martins Fontes, 1996.
} 
A cultura popular, segundo Ginzburg, se define antes de tudo pela sua oposição à cultura letrada ou oficial das classes dominantes, o que confirma a preocupação do autor em recuperar o conflito de classes, numa dimensão sociocultural globalizante. (...) o moleiro Menocchio personifica (...) não a cultura popular em si, mas o complexo processo de circularidade cultural presente num indivíduo que, embora egresso das classes subalternas, sabia ler, e com certeza lera certos textos produzidos no âmbito das classes dominantes, filtrando-os através de valores da cultura camponesa. ${ }^{35}$

Roger Chartier, com o conceito de representação, em sua obra "A História Cultural: Entre Práticas e Representações", afirma que o social só faz sentido nas práticas culturais, e que as classes e grupos só adquirem identidade nas configurações intelectuais nos símbolos de uma realidade contraditória representada. ${ }^{36}$

Segundo Diogo Ruiz:

No Brasil, Sandra Pesavento, em "História e História Cultural”, no decurso de oito capítulos, preocupou-se em refletir as principais contribuições na nova história cultural às pesquisas históricas na contemporaneidade. Segundo Pesavento, as duas principais correntes do pensamento historiográfico criticadas foram o marxismo e o movimento dos Annales, dos quais derivam a nova história cultural, produzida justamente no interior do marxismo inglês refletida em Thompson, e no movimento dos Annales da França. ${ }^{37}$

Assim sendo, podemos afirmar que a História Cultural é um instrumento realmente significativo com as imensas contribuições que dá, mesmo com suas limitações, para o trabalho do historiador nas suas investigações dos rastros e vestígios do passado, e na elaboração dos novos procedimentos de pesquisas enriquecidas com o diálogo em outras áreas do conhecimento.

A História Cultural trouxe uma grande contribuição aos estudos históricos com a inserção de novos objetos e novas fontes. Todas as questões humanas relacionadas ao modo de viver, ou seja, a forma cultural desse viver podem ser pesquisada pelo historiador por meio de suas representações que o fazem enxergar e desvendar significados.

Para reforçarmos essas ideias no presente artigo detivemo-nos também no texto elaborado pela Professora Luciara Silveira de Aragão e Frota ${ }^{38}$ por se tratar de uma análise evolutiva da História e suas disseminações. É um bom marco teórico que vai colaborar com qualquer análise e pesquisa nesses caminhos, iluminando o trabalho do historiador, nas suas buscas infindáveis de temáticas variadas onde se ressaltam a competência e a verdade, nas renovações e nos estudos com novas abordagens e novos objetos incorporados à produção histórica e social.

Chartier é um historiador que transformou no séc. XX, os olhares para conceitos recorrentes na historiografia e teceu novas conotações para a História Cultural.

\footnotetext{
35 VAINFAS, Ronaldo. História das Mentalidades e História Cultural. In: CARDOSO, Ciro Flamarion; VAINFAS, Ronaldo (Orgs.). Domínios da História. Ensaios de teoria e metodologia. Rio de Janeiro: Campus, 1997. p. 152.

${ }^{36}$ CHARTIER, Roger. A História Cultural. Entre práticas e representações. Rio de Janeiro: Bertrand, 1990.

${ }^{37}$ RUIZ, op. cit., 2008.

${ }^{38}$ FROTA, Luciara Silveira de Aragão. História e Mídias, In: AVELINO, Yvone Dias, FLÓRIO, Marcelo; BARREIRO FILHO, Roberto Coelho. (Orgs.) Olhares Cruzados: Cidade, História, Arte e Mídia. Curitiba: Editora CRV, 2011, p 107.
} 
As representações, as práticas culturais e a apropriação, são os três elementos conceituais centrais de suas obras. Enfatiza que a História Cultural Francesa se constitui de uma dupla vertente formada pela História das Mentalidades e pela História serial. A História enquanto disciplina acadêmica era um saber dominante, mas caiu em desprestígio perante a comunidade científica. Era necessário renovar por meio de uma proposta teórico-metodológica.

A História das Mentalidades é, portanto, um entrelaçamento da História com as outras ciências, dando ao historiador possibilidades de adentrar áreas antes não visitadas pela historiografia. Chartier afirma que a História das Mentalidades era então "à investigação da cultura tida como popular; a confiança nos números e na quantificação; o gosto pela longa duração; a primazia atribuída à um tipo de divisão social que organizava impreterivelmente a classificação dos fatos de mentalidade." 39

Essas características consequentemente estão também presentes na História Cultural, cujo principal objetivo é identificar as diferenças de que é constituída uma realidade social, pois existem formas diferentes de perceber esse real. Cabe destacar que as representações do mundo social sempre são determinadas pelos interesses dos grupos que as forjam, ou seja, elas sempre estão entre coerências e competições. Assim sendo a História Cultural não se afasta do social.

Representações são entendidas como matrizes de discursos e práticas diferenciadas e o objetivo delas é a construção do mundo social. Toda essa construção caminha naquilo que Chartier é considerado seu maior representante. Assim, as práticas complexas, múltiplas diferenciadas, constroem e definem o mundo como representação e nesse ponto a importância de Roger Chartier é notória.

Obviamente não podemos esquecer que nada surge do nada. A História que temos hoje é proveniente e herdeira de estudos que remontam a Antiguidade. O saber é construído em um processo somado à muitos autores, perspectivas, objetos e disciplinas. Sempre é bom permitir o encontro e a troca de ideias e fontes. Com todas essas contribuições nos debruçamos nas relações entre História e Literatura com novas publicações, ou seja, na forma de utilizar esta como fonte para o historiador. ${ }^{40}$

As representações e o imaginário político das oposições e das organizações revolucionárias dos anos 1960 e 1970 na América Latina foram marcos importantes na trajetória desses estudos históricos, da produção literária da crítica literária e da produção cinematográfica. Tais representações encontraram suas expressões nas comunidades de exilados, nos seus percursos internacionais e nas repercussões na mídia censurada, no meio acadêmico avido de um saber competente, engajado e transformador.

A historiografia apela à literatura hoje, como mais um registro do real, um instrumento sobre a sua compreensão ou, ainda, como sua metáfora epistemológica. O interesse do historiador em usar a literatura como fonte para suas pesquisas é, grosso modo, recente. Nos idos anos de 1980 a Literatura e a História fundiram-se como área de interesses comuns, e ao mesmo tempo distintas. Caminho importante para os saltos qualitativos dados pela historiografia contemporânea nesta relação. O historiador não pode encarar a obra literária apenas como veículo de conteúdo, pois o valor do texto literário não está propriamente na

\footnotetext{
${ }^{39}$ CHARTIER, Roger. A História Cultural, entre práticas e representações. Lisboa: Difel, 1988.

${ }^{40}$ AVELINO, Yvone Dias. História e Literatura: Cidades, Memória e esquecimentos na América Latina. In: FLORIO, Marcelo. Curitiba: CRV, 2011.
} 
confrontação que dele se pode fazer com a realidade exterior, mas na maneira como essa realidade é abordada, aprofundada, questionada e recriada. Encarar a literatura não como reflexo, mas como refração, como desvio. A literatura aprofunda intuitivamente o conhecimento humano e a História o analisa cientificamente - formas complementares de expressão da realidade do conhecimento.

Partindo-se da ótica da interdisciplinaridade, a tendência moderna é destruir as fronteiras que foram construídas no conhecimento tradicional. Ciências e arte, ficção e verdade aproximam-se sob essa salutar ótica caminham as pesquisas contemporâneas, muito embora alguns historiadores discutam e afirmem em suas reflexões que a História não é ciência, pois, por ser uma narrativa, ela é arte. Alguns pesquisadores adeptos da Nova História Cultural são os que mais defendem a proximidade da História com a Arte e não com a ciência. Bastante complexo e polêmico, pois a História se aproxima do gênero literário e, por ser também narrativa, valoriza a escrita. Vamos refletir, a História busca a verdade, embora esta seja relativa, mas ela prova, ela demonstra, logo é concreta, é refletida, enquanto a literatura fica no campo ficcional por ser arte, e não tem nenhum compromisso com a verdade, mas com a estética.

O historiador, nos dias atuais, lida tranquilamente com as diferentes linguagens que o auxiliam na mediação e na inspiração de suas pesquisas. História e Literatura, embora diferentes, convivem na pesquisa. Tudo é fonte para o historiador que dialoga também com outros campos do conhecimento além da literatura, como a música, a fotografia, as artes plásticas, o teatro, a dança etc.

Conforme afirma a historiadora Vera Lucia Vieira na abertura de uma Semana de História:

O conhecimento da história se renova continuamente através de pesquisas e reflexões teóricas em intercâmbio nacional e internacional. Inúmeras pesquisas de mestrado e doutorado são permanentemente realizadas nos cursos de pós-graduação das universidades, das quais novos conhecimentos sobre a realidade nacional e internacional vêm à tona. Temáticas antes não veiculadas ou mesmo inexistentes aparecem, suscitando novas reflexões e demandando novas abordagens, que questionam ou reforçam fundamentos teóricos e critérios de verdade e objetivação até então desenvolvidos.

$\mathrm{O}$ resultado destas pesquisas, no entanto, pouco é difundido, repousando na sua maior parte nos bancos de dados acadêmicos e nas bibliotecas universitárias a que poucos têm acesso. Em que pesem as possibilidades de divulgação do conhecimento hoje trazidas pela Internet, ainda se verifica uma enorme defasagem entre as reflexões desenvolvidas pelos especialistas e o conhecimento que se torna senso comum, veiculado, por exemplo, por professores de primeiro e segundo graus do ensino público e privado, pelos meios de comunicação de massa e pela sociedade em geral.

Se, por um lado, a população tem pouco acesso a este conhecimento, por outro, as universidades têm escassas condições de divulgá-lo e mesmo debatêlo com um público mais amplo. A defasagem que se verifica entre o número de dissertações e teses defendidas todo ano e a sua transformação em publicações que disponibilizem este conhecimento de forma mais consistente e ampla é enorme. Constata-se que para cada 100 teses defendidas apenas duas se transformam em livro ou são divulgadas mais amplamente.

As possibilidades de acesso a este conhecimento ficam, portanto, reduzidas a um círculo restrito e a função social a que se destina o conhecimento histórico (desenvolver o senso crítico sobre a realidade social a partir da reflexão sobre 
seus fundamentos societários) se inviabiliza pela profunda dicotomia entre os novos conhecimentos e os profissionais que atuam com este saber junto ao grande público, como os envolvidos com a docência de ensino básico.

Estas constatações ficam claras também quando comparamos, por exemplo, o conhecimento veiculado pelos livros didáticos e o resultante das pesquisas realizadas nos cursos de pós-graduação. Apesar da renovação encetada nos últimos anos, ainda se observa um grande distanciamento entre as dimensões abarcadas por estes textos e as da história em uma perspectiva global, mundial e integral, a fim de que a explicação história seja mais científica e atual.

Assim como temos de ser capazes e investigar e explicar o local e o nacional em um contexto mundial, faz-se necessário combinar em nossas indagações e ensinamentos concretos o sujeito individual e o coletivo, o papel histórico inter-relacionado do social e do político, da gente comum e dos grandes homens.

Os historiadores de ofício e professores de história discutem o devir da sociedade, da cultura, da política e têm como dever contribuir para ampliar este conhecimento, a fim de colaborar para que outro mundo seja possível, outra universidade seja possível, outra história seja possível. O historiador constrói a história ao mesmo tempo em que a descobre. Tem, portanto, a obrigação de integrar a recuperação do melhor de nossa tradição historiográfica com os olhos postos sempre no futuro, pois, quando falamos de construir a história como investigadores e como docentes, voltamos ao tema central da necessária colaboração entre historiografia e pedagogia entre investigação e ensino, entre universidade e ensino básico". ${ }^{41}$

\section{Referências}

BOSI, Alfredo. A dialética da colonização. São Paulo: Cia. das Letras, 1992.

BURKE, Peter. A escola dos Annales, a revolução francesa da historiografia (1929-1989). São Paulo: Unesp, 1991.

BURKE, Peter. O que é História Cultural. Rio de Janeiro: Zahar, 2008.

BOURDIEU, Pierre; CHARTIER, Roger. O sociólogo e o historiador. Belo Horizonte: Autêntica, 2015.

CALCLINI, Néstor Garcia. Culturas Híbridas: Estratégias para entrar e sair da Modernidade. São Paulo: EDUSP, 2003.

CARDOSO, Ciro Flamarion; VAINFAS, Ronaldo (Orgs.). Domínios da História, ensaios de teoria e metodologia. Rio de Janeiro: Campus, 1997.

CASTRO, Celso (Org.). Antropologia cultural. BOAS, Franz. Rio de Janeiro: Zahar, 2010.

CERTEAU, Michel de. A escrita da História. Rio de Janeiro: Forense Universitária, 1982.

CHARTIER, Roger. A história cultural entre práticas e representações. Rio de Janeiro: Bertrand. 1990.

CHARTIER, Roger. Entre práticas e representações. Lisboa, Difel, 1988.

CUCHE, Denys. A noção de cultura nas ciências sociais. Bauru: EDUSC, 1999.

DARNTON, Roberto. O beijo de Lamourette, mídia, cultura e revolução. São Paulo: Cia. das Letras, 1990.

\footnotetext{
${ }^{41}$ VIEIRA, Vera Lucia. Conhecimento histórico e realidade: ampliando o debate, texto da XII Semana de História, Departamento de História da PUC/SP, São Paulo: 2005.
} 
DARNTON, Roberto. O grande massacre dos gatos. São Paulo, Paz e Terra, 2014.

DUBY, G. et alii. História e nova história. Lisboa: Teorema, 1986.

ELIADE, Mircea. O mito do eterno retorno. Lisboa: Edições 70, 1999.

FREYRE, Gilberto. Casa Grande \& Senzala. Rio de Janeiro: José Olympio, 1961.

GINZBURG, Carlo. O Queijo e os Vermes. O cotidiano e as ideias de um moleiro perseguido pela inquisição. São Paulo: Cia. das Letras, 1987.

HALL, Stuart. Cultura e representação. Rio de Janeiro: PUC/Rio: 2016.

HUNT, Lynn. A Nova História Cultural. São Paulo: Martins Fontes, 1992.

LE GOFF, Jacques; NORA Pierre. História: Novos Problemas. Rio de Janeiro: Livraria Francisco Alves, 1987.

PINSKY, Carla B. (Org.). O historiador e suas fontes. São Paulo: Contexto, 2010.

PINSKY, Carla B.; LUCA, Tânia Regina (Orgs.). O historiador e suas fontes. São Paulo: Contexto, 2009.

PATRIOTA, Rosangela; RAMOS, Alcides Freire (Orgs.). Escritos da História: ver, sentir, narrar. São Paulo: Hucitec, 2014.

PESAVENTO, Sandra Jatahy. História e História Cultural. Belo Horizonte: Autêntica, 2014.

REIS, José Carlos. Escola dos Annales, a inovação em História. São Paulo: Paz e Terra, 2000.

ROIZ, Diogo da Silva. A nova história cultural: questões e debates. In: Pensamento plural. Pelotas, jan/jun. 2008. p. 181.

VIEIRA, Vera Lucia. Conhecimento história e realidade social: ampliando o debate. Departamento de História, XII Semana de História. São Paulo: 2005. 